\title{
The Amino Acid Transporter OsAAP4 Contributes to Rice Tillering and Grain Yield by Regulating Neutral Amino Acid Allocation through Two Splicing Variants
}

\author{
Zhongming Fang ${ }^{1,2^{*}+}\left(\mathbb{D}\right.$, Bowen $\mathrm{Wu}^{1,2+}$ and Yuanyuan $\mathrm{Ji}^{2+}$
}

\begin{abstract}
Background: Amino acids, which are transported by amino acid transporters, are the major forms of organic nitrogen utilized by higher plants. Among the 19 Amino Acid Permease transporters (AAPs) in rice, only a small number of these genes have been reported to influence rice growth and development. However, whether other OsAAPs are responsible for rice growth and development is unclear.

Results: In this study, we demonstrate that OsAAP4 promoter sequences are divergent between Indica and Japonica, with higher expression in the former, which produces more tillers and higher grain yield than does Japonica. Overexpression of two different splicing variants of OsAAP4 in Japonica ZH11 significantly increased rice tillering and grain yield as result of enhancing the neutral amino acid concentrations of Val, Pro, Thr and Leu. OsAAP4 RNA interference (RNAi) and mutant lines displayed opposite trends compared with overexpresing (OE) lines. In addition, exogenous Val or Pro at $0.5 \mathrm{mM}$ significantly promoted the bud outgrowth of lines overexpressing an OsAAP4a splicing variant compared with ZH11, and exogenous Val or Pro at $2.0 \mathrm{mM}$ significantly enhanced the bud outgrowth of lines overexpressing splicing variant OSAAP4b compared with $\mathrm{ZH} 11$. Of note, the results of a protoplast amino acid-uptake assay showed that Val or Pro at different concentrations was specifically transported and accumulated in these overexpressing lines. Transcriptome analysis further demonstrated that OsAAP4 may affect nitrogen transport and metabolism, and auxin, cytokinin signaling in regulating rice tillering.
\end{abstract}

Conclusion: Our results suggested that OSAAP4 contributes to rice tiller and grain yield by regulating neutral amino acid allocation through two different splicing variants and that OSAAP4 might have potential applications in rice breeding.

Keywords: Amino acid, Transporter, Rice, Tiller, Outgrowth bud, Grain yield, Splicing variants

\footnotetext{
* Correspondence: zmfang@gzu.edu.cn

${ }^{\dagger}$ Zhongming Fang and Bowen Wu contributed equally to this work.

${ }^{1}$ Key Laboratory of Plant Resource Conservation and Germplasm Innovation

in Mountainous Region (Ministry of Education), College of Agricultural

Sciences, Guizhou University, Guiyang 550025, China

${ }^{2}$ National Key Laboratory of Crop Genetic Improvement, Huazhong

Agricultural University, Wuhan 430070, China
}

\section{Springer Open}

(c) The Author(s). 2021 Open Access This article is licensed under a Creative Commons Attribution 4.0 International License, which permits use, sharing, adaptation, distribution and reproduction in any medium or format, as long as you give appropriate credit to the original author(s) and the source, provide a link to the Creative Commons licence, and indicate if changes were made. The images or other third party material in this article are included in the article's Creative Commons licence, unless indicated otherwise in a credit line to the material. If material is not included in the article's Creative Commons licence and your intended use is not permitted by statutory regulation or exceeds the permitted use, you will need to obtain permission directly from the copyright holder. To view a copy of this licence, visit http://creativecommons.org/licenses/by/4.0/. 


\section{Background}

Nitrogen is one of the limiting nutrients for plant growth and development. Higher plants take up inorganic nitrogen, including nitrate and ammonium; this is followed by nitrogen assimilation into amino acids, the main form of organic nitrogen transport, in the root and transport and reallocation from source organs to sinks via the xylem and phloem (Xu et al. 2012; Tegeder and Masclaux-Daubresse, 2018). Plants also acquire amino acids directly from the soil (Tegeder and Rentsch, 2010). Amino acids are the main components of the enzymes and proteins involved in plant metabolism and structure and also serve as precursors for the synthesis of a large variety of compounds critical to plant development, including nucleotides, chlorophyll, and secondary metabolites such as hormones and lignin (Tegeder, 2012; Pratelli and Pilot, 2014; Jin et al. 2019). Amino acid transporters play an important role in the transmembrane transport of amino acids, which are involved directly or indirectly in processes of nitrogen metabolism that are crucial for plant growth and development. Such processes include assimilation and partition of amino acids within the cell, translocation of amino acids over short and long distances, and uptake and usage of amino acids by sink organs (Tegeder, 2014; Tegeder and Masclaux-Daubresse, 2018). Recent studies have shown that increasing phloem and embryo loading with amino acids may increase biomass and seed yield (Zhang et al. 2015; Perchlik and Tegeder, 2017; Tegeder and Masclaux-Daubresse, 2018).

Amino acid permease (AAP), a member of the amino acid transporter (AAT) family, has been extensively studied functionally in plants. AAPs have been suggested to be involved in a number of physiological processes in plants, including amino acid uptake from the soil, phloem loading or xylemphloem transfer, and seed loading (Tegeder and Rentsch 2010). In Arabidopsis thaliana, 8 AAP transporters (AtAAP1-AtAAP8) are reported to have important functions in the translocation of different amino acids for organic nitrogen utilization in source and sink organs. For example, it has been demonstrated that AtAAP1 imports neutral, uncharged amino acids into root cells and developing embryos and is important for storage protein synthesis and seed yield in Arabidopsis (Hirner et al. 1998; Lee et al. 2007; Sanders et al. 2009). AtAAP2 was found to transport Glu and neutral amino acids and be very important for amino acid transport from the xylem to phloem (Fischer et al. 2002; Zhang et al. 2010). In addition, AtAAP3 mediates the uptake of neutral and basic amino acids (Okumoto et al. 2004), AtAAP4 imports neutral amino acids Pro and Val (Fischer et al. 1995), and broad-affinity AtAAP5 transports anionic, neutral and cationic amino acids (Fischer et al. 1995; Boorer and Fischer, 1997; Svennerstam et al. 2008). AtAAP6 reportedly affects the Lys, Phe, Leu and Asp contents of sieve elements and regulates rosette width and seed volume in Arabidopsis
(Hunt et al. 2010), and AtAAP8, a high-affinity transporter of acidic amino acids, is important for seed development and yield (Okumoto et al. 2002; Schmidt et al. 2007; Santiago and Tegeder, 2016).

In Vicia faba, VfAAP1 and VfAAP3 transport a broad range of amino acids, though VfAAP1 has a preference for Cys and VfAAP3 for Lys and Arg (Miranda et al. 2001). StAAP1 is expressed in mature leaves, and antisense inhibition of this gene decreases the amino acid content of transgenic Solanum tuberosum (Koch et al. 2003). PvAAP1 is expressed in epidermal cells, xylem parenchyma cells, and phloem and is involved in xylem-phloem transfer and phloem loading for amino acid transport to sink tissues in Phaseolus vulgaris (Tan et al. 2008). It was also proposed that PtAAP11 plays a major role in xylem formation by providing Pro in Populus trichocarpa (Couturier et al. 2010). Recently, it was found that overexpression of PSAAP1 positively regulated amino acid transport from source to sink organs and influenced plant nitrogen use efficiency in Pisum sativum (Perchlik et al. 2017), and PsAAP6 functions in nodule nitrogen metabolism and export and plant nutrition (Garneau et al. 2018).

Among rice 19 AAP transporters in rice, OsAAP6 was reported to affect the distribution of various amino acids in plants and to function as a positive regulator of the grain protein content and grain quality in rice (Peng et al. 2014). OsAAP3 mainly transports basic amino acids Lys and Arg (Taylor et al. 2015), and recent studies demonstrated that blocking OsAAP3 or OsAAP5 expression increases grain yield by regulating the concentrations of these two amino acids (Lu et al. 2018; Wang et al. 2019a). Moreover, the amino acid transporter OsAAP1 mediate growth and grain yield by regulating neutral amino acid uptake and reallocation in rice (Ji et al. 2020). In rice, in addition to OsAAPs, OsLHT1 has been shown to function in amino acid root uptake and source-to-sink allocation (Liu et al. 2005; Wang et al. 2019b; Guo et al. 2020a, 2020b). In this study, we found the promoter sequences of OsAAP4 to be divergent between Indica and Japonica, resulting in higher expression of OsAAP4 in Indica, which produced more tillers and higher grain yield than did Japonica. Moreover, two variants of OsAAP4 mainly regulated neutral amino acid Val and Pro within different concentration ranges and significantly increased grain yield by promoting bud outgrowth and increasing tiller number. OsAAP4 might have potential applications in rice breeding to increase grain yield especially in plants grown in soil with abundant organic nitrogen.

\section{Results}

The Expression Level of OsAAP4 Positively Correlated with Rice Tillering and Grain Yield between Indica and Japonica

Overall, 533 rice accessions according to Rice Variation Map v2.0 (a database for rice genome variation) were 
used in this study (Chen et al. 2014). First, we analyzed the promoter and exon sequences of OsAAP4 in all 533 accessions and identified 5 haplotypes in 497 accessions (Fig. 1a). Among these materials, 35 single-nucleotide polymorphisms (SNPs) were detected in haplotypes 1 to 5 (Hap1-Hap5) (Fig. 1a). Surprisingly, Hap2 was found to be mainly present in Indica accessions, whereas was Hap5 mainly found in Japonica accessions (Fig. 1a). These results indicate various divergences of OsAAP4 promoter sequences between Indica and Japonica. We then detected tiller number per plant (Fig. 1b) and weight of shoot per plant (Fig. 1c) in the aboveground parts at filling stage, total weight per plant (Fig. 1d) and grain yield per plant (Fig. 1e) at mature stage of Hap1 to Hap5-type cultivar seedlings and found that the tiller number, weight of shoot, total weight, grain yield in Indica (Hap2) was significantly higher than that in Japonica (Hap5, Fig. 1b-e). Furthermore, We chose seedlings at the vegetative stage to detect expression of OsAAP4 from Hap1 to Hap5 and found that OsAAP4 expression in Indica accessions (Hap2) was significantly higher than that in Japonica cultivars (Hap5, Fig. 1f). In addition, we randomly selected ten Indica and ten $\mathrm{Ja}$ ponica cultivars to assess the association of OsAAP4

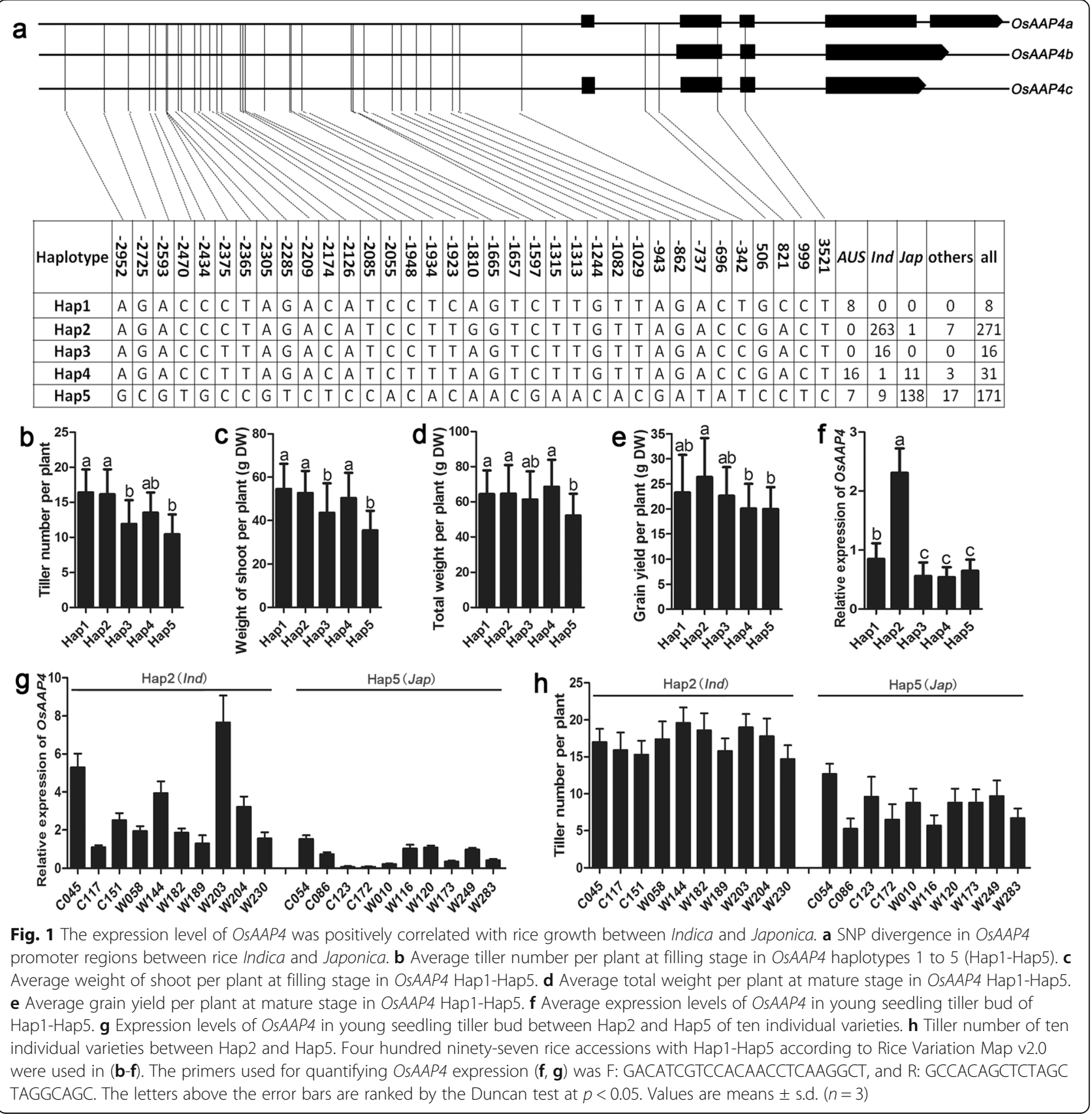


expression level with tiller number in seedlings of different Haps and found that the expression levels of OsAAP4 in the Indica cluster with Hap2 were higher than those in the Japonica cluster with Hap5 (Fig. 1g). Moreover, the expression levels of OsAAP4 in Hap2Indica accessions were higher than those in Hap5-Japonica accessions at basal part of seedlings (Supplementary file 1: Figure S1b). However, no difference of OsAAP4 expression levels bewteen Hap2 and Hap5 accessions was observed at root, old leaf, and young leaf of seedlings (Supplementary file 1: Figure S1a, c-d). Similarly, tiller number per plant were higher in seedlings of Indica accessions that carried Hap2 compared to Japonica accessions carrying Hap5 (Fig. 1h). These results demonstrated that Indica accessions with Hap2 more highly expressed OsAAP4, which was accompanied by higher tiller numbers and grain yield, than Japonica accessions, indicating that OsAAP4 expression levels are positively correlated with both tiller development and grain yield in rice.

\section{The Expression Pattern of OsAAP4 and Subcellular Localization of the Protein}

To further compare OsAAP4 promoter activity between Hap2 and Hap5, we amplified promoter sequences by PCR and performed sequencing (Supplementary file 2: Figure S2). The results showed that the promoter sequence of the Hap5 type in Japonica was the same as that of Japonica Nipponbare, which has been sequenced (https://phytozome.jgi.doe.gov/pz/portal.html). However, there were many SNP differences in the sequence of Hap2 type in Indica, with also base insertion and deletion in the promoter region of Hap2 compared with Hap5 (Supplementary file 2: Figure S2). Therefore, a promoter-GUS plasmid of Hap2 type of OsAAP4 was constructed and transformed into Japonica ZH11. GUS staining revealed a particularly strong signal in the root tip (Fig. 2a), lateral root (Fig. 2b, c), and young tiller bud (Fig. 2d) at the vegetative stage and the leaf blade (Fig. 2f), leaf sheath (Fig. 2g), stem (Fig. 2h) and panicle (Fig. 2i) at the reproductive stage. Additionally, GUS activity was abundant in the parenchymal cells of the cortex in a transverse section of the root (Fig. 2j, k) and was enriched in the xylem and phloem of vascular tissue in the leaf sheath (Fig. 2l), leaf blade (Fig. 2m), stem (Fig. $2 \mathrm{n}$ ), and young panicle (Fig. 2o).

Next, we detected the levels of three splicing variants for the OsAAP4 gene in various tissues. Expression levels of the longest variant OsAAP4a were higher in the root, tiller basal part, tiller bud, and leaf at the vegetative stage in Japonica ZH11, but the levels of the moderate-length variant $O s A A P 4 b$ were higher in the root, tiller basal part, and leaf at the vegetative stage and the leaf and panicle at the reproductive stage (Fig. 2p). The expression level of the shortest splicing variant OsAAP4c was lower in various tissues (Fig. 2p). Besides, the expression levels of OsAAP4a or OsAAP4b in the basal part for tiller bud elongation in hap2 varieties were higher than those in hap5 varieties (Supplementary file 3: Figure S3). We also observed enrichment of green fluorescence signals of OsAAP4a-GFP and OsAAP4b-GFP both in the plasma membrane and the nucleus (Supplementary file 4: Figure S4). These results indicated that OsAAP4 more likely mediates amino acid membrane allocation from roots through parenchymal cells and reallocates amino acids from source organs to sinks via the xylem and phloem.

OsAAP4 Positively Regulated Rice Tillering and Grain Yield To further understand the effects of altered OsAAP4 expression on rice growth and development, we generated longer variant $\mathrm{OEa}$ (over-expression), shorter variant $\mathrm{OEb}$ (over-expression) and $\mathrm{Ri}$ (common sequence of the two variants of RNAi) transgenic lines of OsAAP4 under the control of rice $35 \mathrm{~S}$ and $U b i-1$ promoters. Compared with wild-type ZH11, OEa and OEb lines showed significantly higher tiller numbers at the reproductive stage, whereas the two Ri lines exhibited reduced numbers of tiller (Fig. 3a, d). Moreover, we detected the expression levels of OsAAP4 in the transgenic plants and found that the OEa and OEb lines for each variant showed significantly higher expression levels than did wild-type ZH11 but that the Ri lines showed markedly reduced levels of OsAAP4 expression than ZH11 (Fig. 3c). In addition, overexpression of OsAAP4 in $\mathrm{OEa}$ and $\mathrm{OEb}$ lines resulted in enhanced filled grain number and grain yield per plant compared with ZH11 (Fig. 3e, f). More importantly, nitrogen utilization efficiency (NUtE) was significantly improved in OsAAP4 OEa and OEb lines compared with ZH11; however, Ri lines showed reduced NUtE than ZH11 (Fig. 3g). To further investigate the impact of OsAAP4 on rice growth and development, we established a CRISPR line of the common sequence of the two variants of OsAAP4 (Supplementary file 5: Figure S5) and found that OsAAP4 knockout significantly decreased tiller number (Supplementary file 5: Figure S5b, d), filled grain number (Supplementary file 5: Figure S5c, e), grain yield (Supplementary file 5: Figure S5c, f), and NUtE (Supplementary file 5: Figure S5g) compared to ZH11. Similarly, tiller number per plant were higher in OEa and OEb lines compared to ZH11 at the reproductive stage, whereas the two Ri lines and osaap4 exhibited reduced numbers of tiller when rice plants were grown in Sanya, China (Supplementary file 6: Figure S6).

\section{Two Variants of OsAAP4 OE Lines Promoted Bud Outgrowth under Different Neutral Amino Acid Concentrations}

To further investigate the amino acids accompanying enhanced expression levels of OsAAP4 in rice growth 

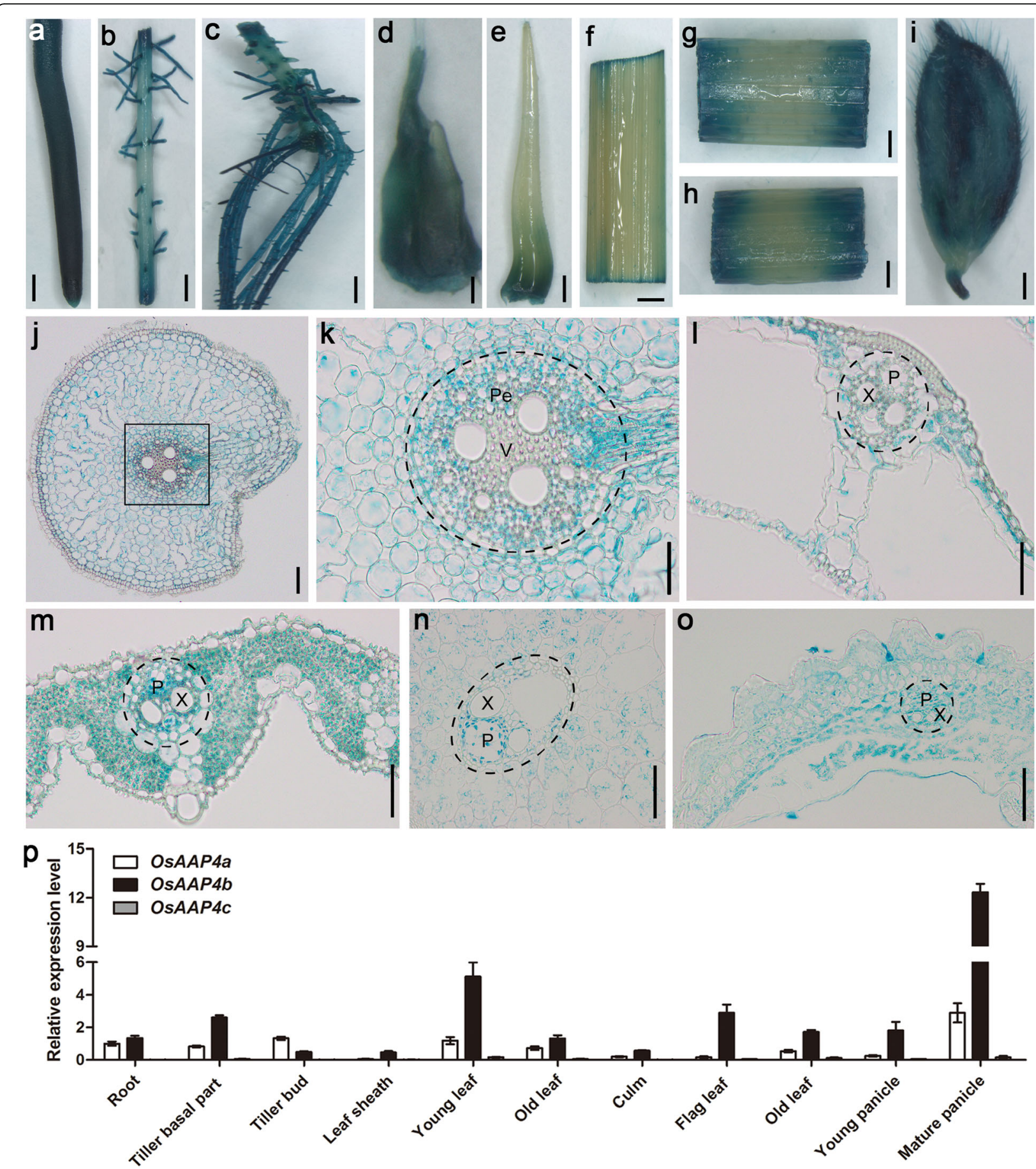

Fig. 2 Promoter-GUS analysis and relative expression level of OsAAP4. OsAAP4 promoter-GUS staining in the root tip (a), lateral root (b), adventitious roots (c),

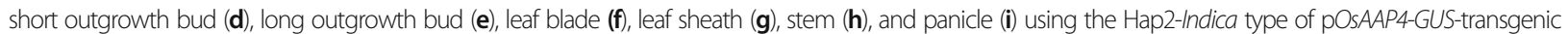

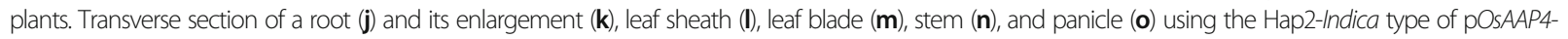
GUS transgenic plants. $\mathbf{p}$ The expression pattern of OSAAP4 in different tissues of Japonica ZH11. The primers used for quantifying OSAAP4a expression was F: TGGCACTCACCCTTGCACAC, and R: CCGTCCACACCGTCCCTTGT, for quantifying OSAAP4b expression was ACTTGAGCTCTCTGCATTGGGT, and R: AGCGGTAGCA ATTGGCGAGGA, and for quantifying OsAAP4b + c expression was TTGCTGCAGGTGTTCGCGCA, ATCGTCCGCAGCACCAGCTTCAG which primers were designed for common sequences between two splice variants OsAAP4b and OSAAP4C. OsAAP4C of the two splice variants accounts for half of the expression level for both the splice variants. Pe indicates pericycle, $V$ indicates vascular, $X$ indicates $x y l e m$, and $P$ indicates phloem in (k-o). Scale bars, $0.5 \mathrm{~cm}(\mathbf{a}-\mathbf{c}, \mathbf{f}-\mathbf{h}), 0.2 \mathrm{~cm}(\mathbf{d}), 0.1$ $\mathrm{cm}(\mathbf{e}, \mathbf{i}), 50.0 \mu \mathrm{m}(\mathbf{j}), 20.0 \mu \mathrm{m}(\mathbf{k}-\mathbf{o})$ 


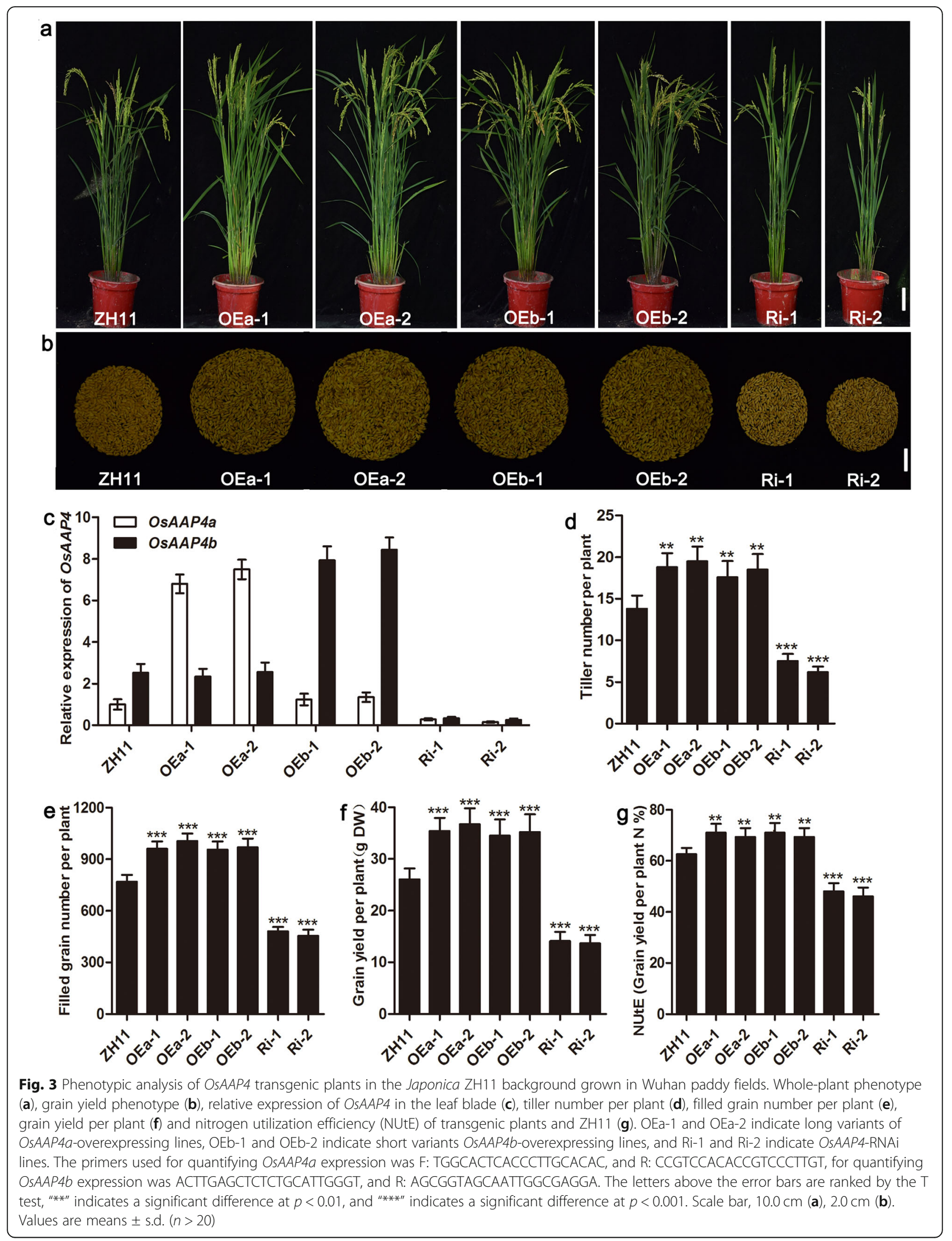




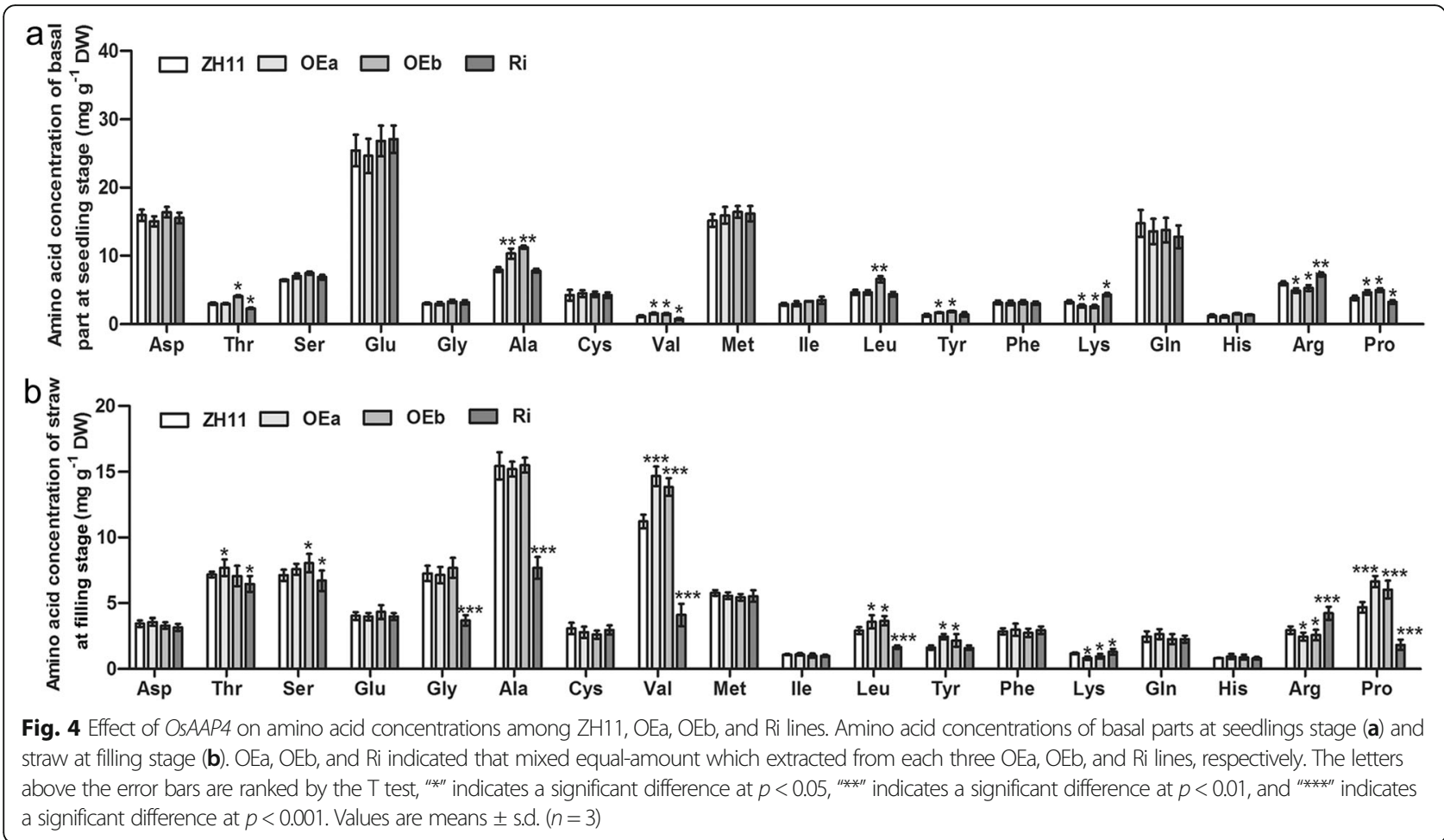

and development, we measured the concentration of individual amino acids in the basal parts at seedling stage and straws at aboveground parts of transgenic plants. The results showed that concentrations of neutral amino acids Thr, Val, Leu, Tyr, and Pro were higher in OEa or $\mathrm{OEb}$ than in ZH11, however, the concentrations of basic amino acids Lys and Arg were significantly decreased when compared with levels in ZH11 (Fig. 4). In contrast, the concentrations of neutral amino acids Thr, Val, and Pro in $\mathrm{Ri}$ line seedlings were significantly decreased compared with those of ZH11 (Fig. 4). Moreover, accumulation of basic amino acids Lys and Arg was found in Ri line seedlings compared to ZH11 (Fig. 4). In addition, the concentrations of total amino acids were higher in OEa and OEb compared with ZH11, but lower concentrations of total amino acids in Ri (Supplementary file 7Figure S7). These results indicated that the concentrations of Val and Pro increased most significantly in the $\mathrm{OE}$ line and decreased in the Ri line, suggesting that overexpression of OSAAP4 might promote the allocation of neutral amino acids Val and Pro to further support plant growth and enhance grain yield. However, Ri lines suppressing OsAAP4 showed decreased contents of neutral amino acids Val and Pro and enhanced contents of basic amino acids Lys and Arg to balance the total amino acid content in seedlings.

As the number of tillers in $\mathrm{OE}$ lines increased at the reproductive stage compared to that in ZH11 (Fig. 3), we further validate the effect of Val and Pro on bud outgrowth for tillering among different OsAAP4 expression lines, exogenous Val and Pro was applied. Interestingly, both the first bud and second bud length of OEa line increased under the $0.5 \mathrm{mM}$ Val treatment compared with OEb line. However, the first bud and second bud length in OEb line increased when the concentration of Val was 2.0 $\mathrm{mM}$ compared with OEa line (Fig. 5a, c, d), and results similar those for Val were observed at 0.5 or $2.0 \mathrm{mM}$ Pro (Fig. 5b, e, f). Additionally, the first and second bud lengths of the Ri line decreased when compared with $\mathrm{ZH} 11$ at these concentrations of amino acids treatments (Fig. 5). Besides, the plant height and biomass of OEa and OEb lines were notably increased compared with that of wild-type ZH11 under Val $0.5 \mathrm{mM}$ treatment after 6 weeks (Supplementary file 8: Figure S8a, e, f), but these aspects were significantly reduced compared with ZH11 under Val 2.0 mM treatment (Supplementary file 8: Figure $\mathrm{S} 8 \mathrm{~b}, \mathrm{e}, \mathrm{f})$. In addition, $0.5 \mathrm{mM}$ Pro strongly increased plant height and biomass only in OEa plants (Supplementary file 8: Figure S8c, g, h) and $2.0 \mathrm{mM}$ Pro significantly promoted plant height and biomass in OEb plants (Supplementary file 8: Figure S8d, g, h) compared with ZH11 after 6 weeks. No obvious effect on plant height and biomass of the OsAAP4 Ri lines compared with $\mathrm{ZH} 11$ was found for $0.5 \mathrm{mM}$ Pro treatment (Supplementary file 8: Figure S8g, h), but $2.0 \mathrm{mM}$ Pro significantly decreased the biomass of Ri lines compared with ZH11 (Supplementary 


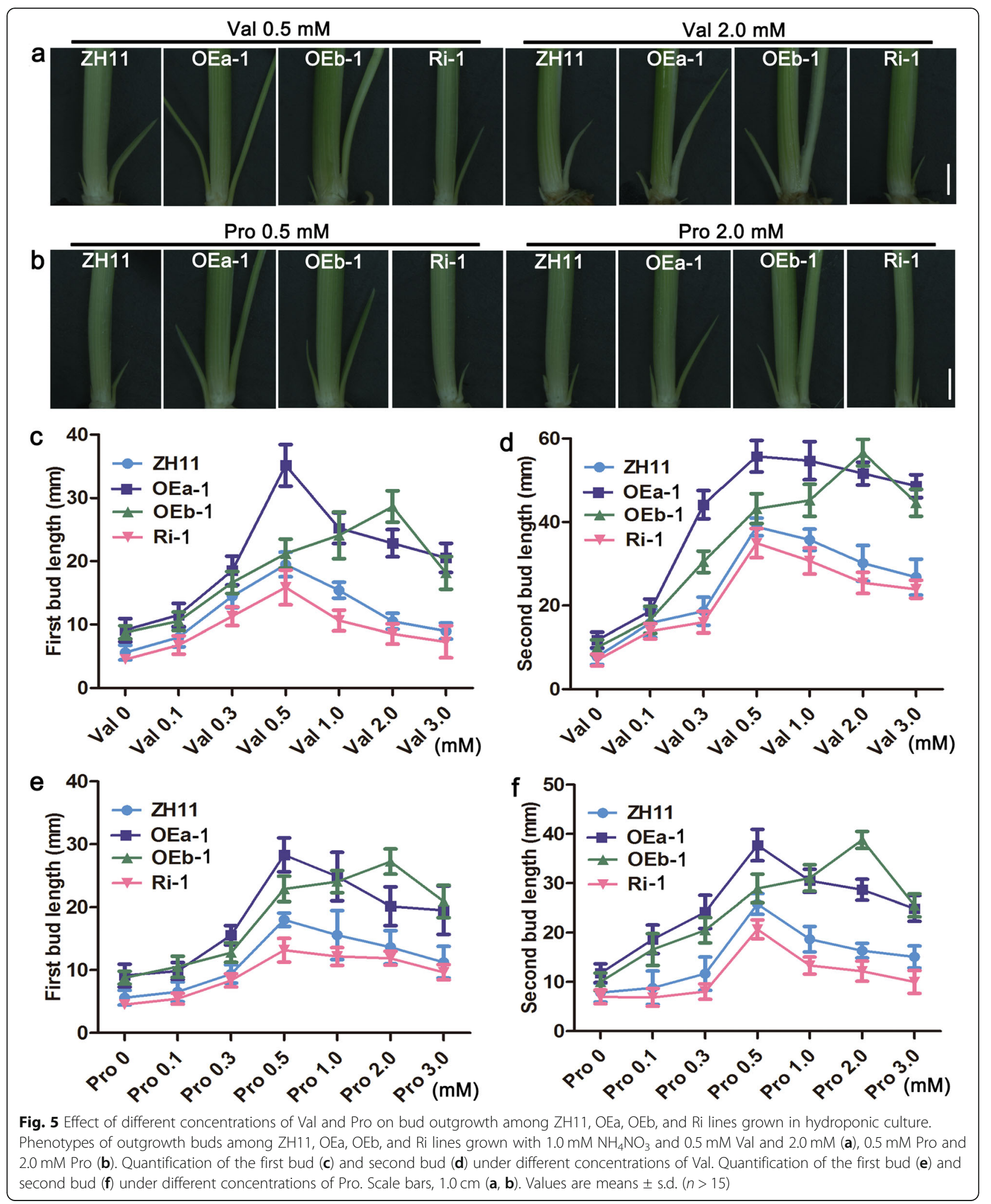

file 8: Figure S8h). Analysis of bud outgrowth, plant height and biomass revealed that elevated expression of OsAAP4a facilitates rice tillering at lower concentrations of Val and Pro $(0.5 \mathrm{mM})$ but that OsAAP4b facilitates rice tillering at higher amino acid concentrations of $\mathrm{Val}$ and Pro $(2.0 \mathrm{mM})$. Interestingly, the two splicing variants 

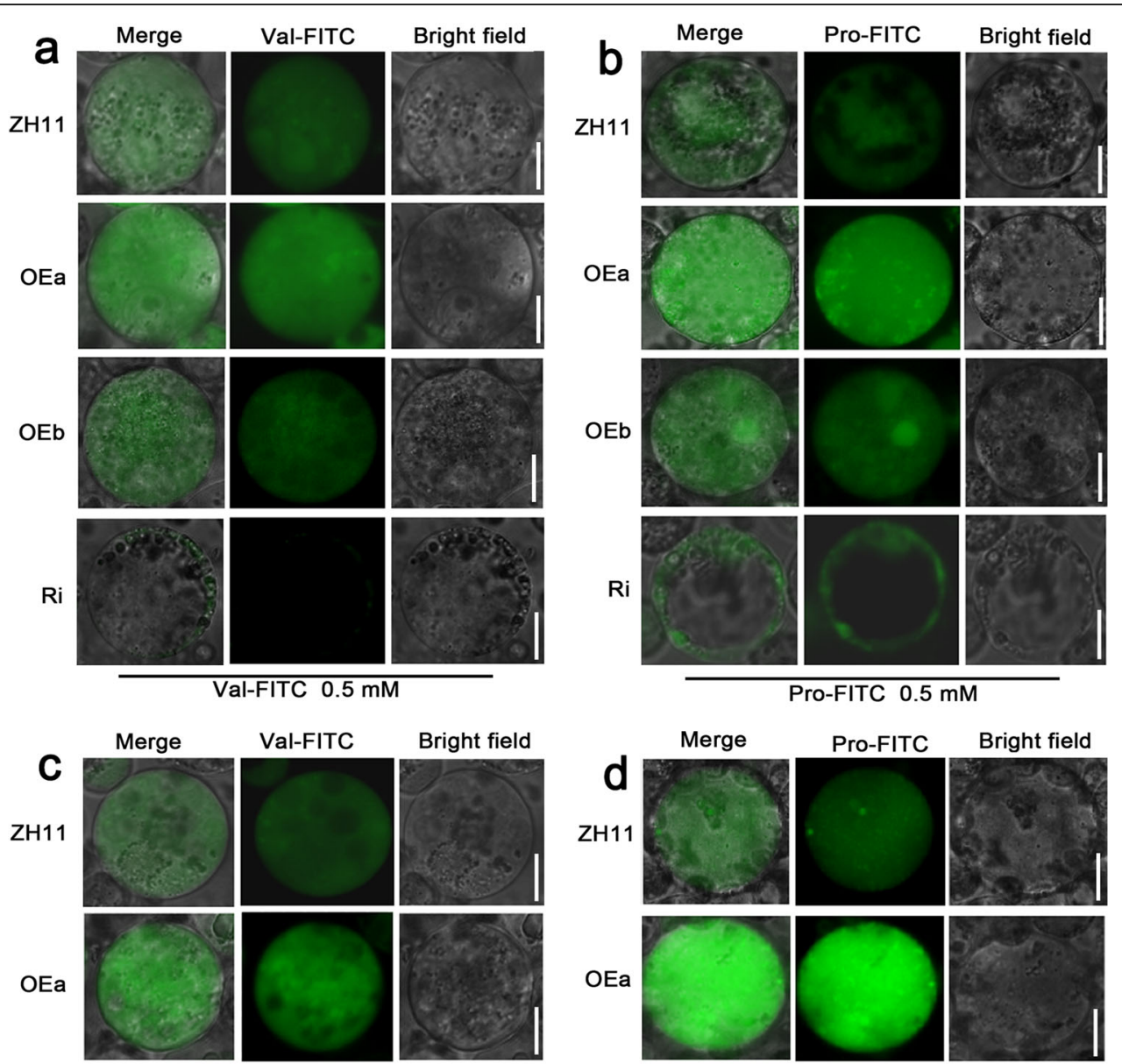

$\mathrm{OEb}$
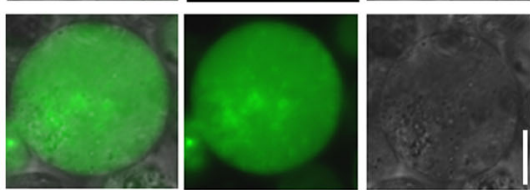

Ri
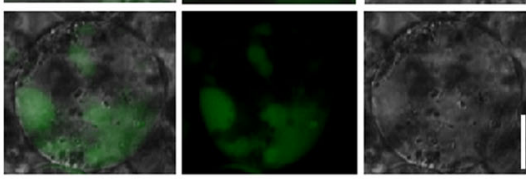

Val-FITC $2.0 \mathrm{mM}$

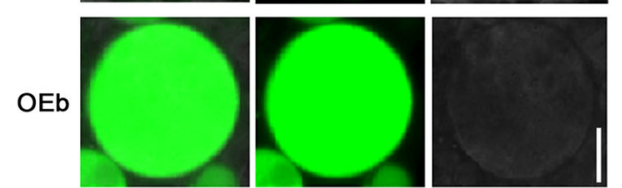

$\mathrm{Ri}$
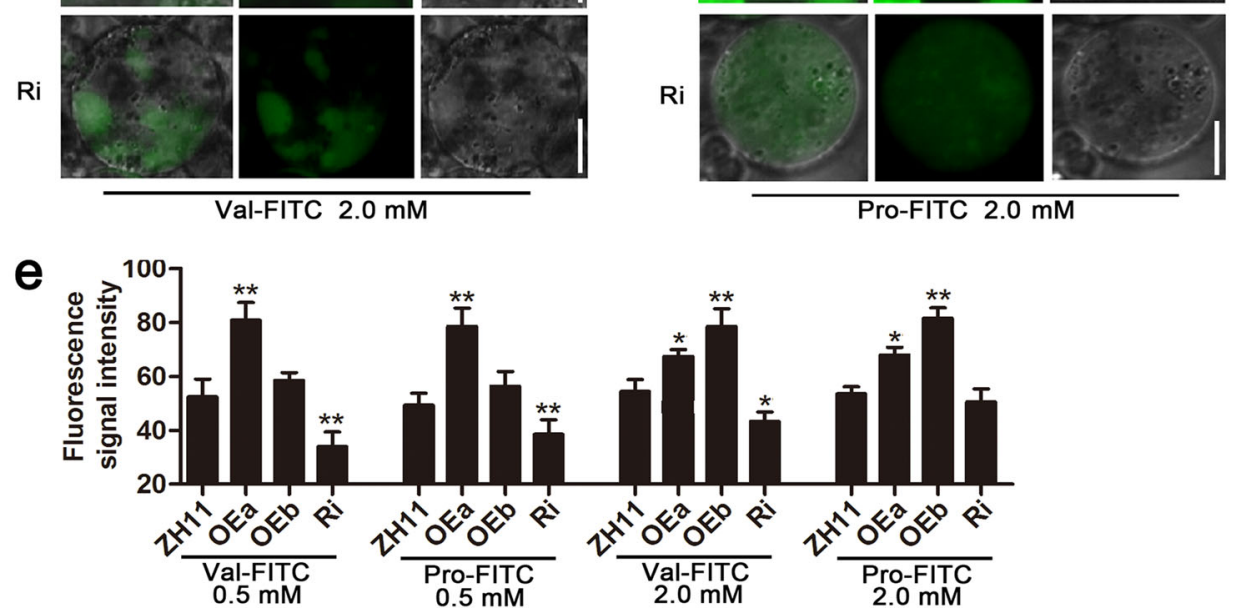

Fig. 6 Protoplast amino acid-uptake assay among ZH11, OEa, OEb, and Ri lines. Fluorescence was detected after culturing protoplasts with FITClabeled amino acids for $4 \mathrm{~h}$. Green fluorescence images of ZH11 and OEa, OEb and Ri lines under treatment with $0.5 \mathrm{mM}$ Val-FITC (a), $0.5 \mathrm{mM}$ ProFITC (b), $2.0 \mathrm{mM}$ Val-FITC (c), and $2.0 \mathrm{mM}$ Pro-FITC (d). e Detection of cell fluorescence signal intensity in (a-d). Fluorescence intensities were normalized to the area of the respective cell by ImageJ software, and a total of 100 cells were statistically analyzed. Scale bars, 5.0 um (a-d). The letters above the error bars are ranked by the T test, " $* *$ indicates a significant difference at $p<0.05$, and "**" indicates a significant difference at $p<0.01$. Values are means \pm s.d. $(n=3)$ 


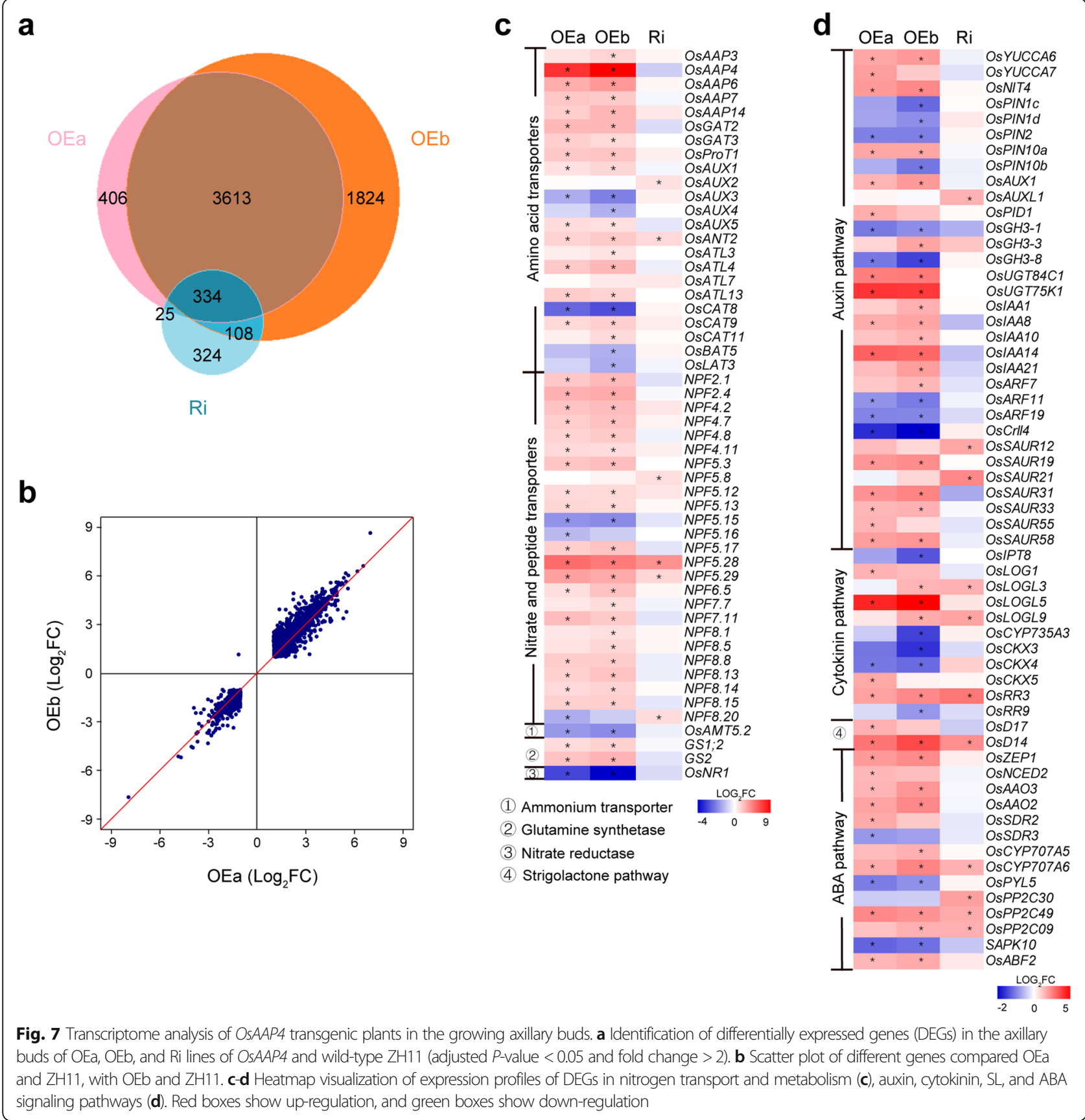

displayed different sensitivities to different amino acid concentrations. Taken together, these results demonstrated that two OE line variants promoted rice tillering under different concentrations of Val and Pro.

\section{Both Variants of OsAAP4 Might Regulate Neutral Amino Acids to Support Rice Tillering}

The protoplast-amino acid-FITC assay is a new method for examining plant amino acid transporters (Wang et al. 2019a; Ji et al. 2020). To further validate that OsAAP4 mediates Val and Pro transport, a protoplast amino acid-uptake assay was performed. Protoplasts were cultured with $0.5 \mathrm{mM}$ and $2.0 \mathrm{mM}$ fluorescein isothiocyanate (FITC)-labeled amino acids, Val-FITC and Pro-FITC. Stronger fluorescence signals in the cytoplasm were detected in the protoplasts of OEa lines cultured with $0.5 \mathrm{mM}$ Val-FITC and $0.5 \mathrm{mM}$ Pro-FITC for $4 \mathrm{~h}$ than those of the ZH11 and OEb lines, and the FITC signal was weaker in Ri lines than in ZH11 (Fig. 6a, b, e). Interestingly, when protoplasts were cultured with each FITC-labeled amino acid at $2.0 \mathrm{mM}$ (Val-FITC, ProFITC) for $4 \mathrm{~h}$, OEb lines presented stronger fluorescence 
signals than did ZH11 and OEa lines, and the opposite was found for Ri lines (Fig. 6c, d, e).

As the concentrations of amino acids Arg, Lys, Thr and Leu in OsAAP4 transgenic plants also changed, protoplasts were cultured with Arg-FITC, Lys-FITC, ThrFITC and Leu for amino acid transport of OsAAP4. We detected higher fluorescence signal intensity in the protoplasts of the Ri lines cultured with Lys-FITC and ArgFITC than in ZH11 protoplasts, and the FITC signal was weaker in the OE lines than in ZH11 (Supplementary file 9: Figure S9a, b, e). However, higher fluorescence signal intensity in the protoplasts of the $\mathrm{OE}$ lines cultured with Thr-FITC and Leu-FITC than in ZH11 protoplasts, and FITC signal were lower in the Ri lines than in ZH11 (Supplementary file 9: Figure S9c, d, e). These results indicated that OsAAP4 might played a crucial role in regulating neutral amino acids in rice plant cells of different variants at different concentrations.

\section{OsAAP4 Regulates Bud Outgrowth and Rice Tillering by Coordinating Nitrogen and Phytohormone Pathway}

To investigate the mechanism of OsAAP4 in regulating bud outgrowth, we performed RNA-seq using RNA samples from the tiller buds of the OsAAP4 OE lines, $\mathrm{Ri}$ lines and the wild-type ZH11. A total of 334 genes were differentially expressed between $\mathrm{OEa}, \mathrm{OEb}$ and RNAi lines, and 3613 co-regulated downstream genes between $\mathrm{OEa}$ and $\mathrm{OEb}$, however, OEb regulated more downstream genes (Fig. 7a). Scatter plot results showed that the gene patterns of $\mathrm{OEa}$ and $\mathrm{OEb}$ were very similar compared with ZH11 (Fig. 7b). To understand the biological functions of these Differentially Expressed Genes (DEGs), we performed Kyoto Encyclopedia of Genes and Genomes (KEGG) pathway enrichment analysis. The DEGs were assigned to one KEGG pathways (metabolic pathways) in OsAAP4 OEa lines (Supplementary file 10: Figure S10a), 12 KEGG pathways, such as metabolic pathways, biosynthesis of secondary metabolites, Val, Leu and Ile degradation in OsAAP4 OEb lines (Supplementary file 10: Figure S10b), 40 KEGG pathways, such as metabolic pathways, biosynthesis of secondary metabolites, Arg and Pro metabolism, Gly, Ser and Thr metebolism, and plant hormone signal transduction in both OsAAP4 OEa and OEb lines (Supplementary file 11: Figure S11). To further investigate the mechanism of OsAAP4 in regulating bud outgrowth, we analyzed the expression patterns of DEGs in $\mathrm{N}$ transport and metabolism, and the heatmap result showed that many amino acid transporters genes (such as OsAAP4 and OsAAP7), nitrate and peptide transporters genes (such as OsNPF2.4, OsNPF6.5, and OsNPF7.7), glutamine synthetase genes (OsGS1;2 and OsGS2) had increased expression in $\mathrm{OEa}$ or $\mathrm{OEb}$ lines, but reduced expression in $\mathrm{Ri}$ lines (Fig. 7c; Supplementary file 12: Figure S12), which indicated that altered expression of OsAAP4 may influence the expression of other nitrogen transport genes and the glutamine synthetases needed for the regulation of the axillary bud outgrowth. In addition, the heatmap result showed that YUCCA auxin biosynthetic genes were up-regulated in the OsAAP4 $\mathrm{OE}$ lines compared with the wild-type ZH11 (Fig. 7c), indicating that auxin may be decreased in the axillary buds of OsAAP4 OE lines, leading to the down-regulation of the auxin transporter PIN genes (Fig. 7c), and resulting in the induction of the axillary bud outgrowth (Fig. 7c). Besides, the decreased expression of OsCKX3 and OsCKX4 may promote the cytokinin signaling, leading to the promotion of axillary bud outgrowth of OsAAP4 OE lines (Fig. 7c). Moreover, the expression of the ABA biosynthesis and signaling genes was decreased to promote the bud outgrowth of OsAAP4 OE lines (Fig. 7c). In order to further determine whether there is a regulatory relationship between OsAAP4 and OsAAP3 or OsAAP5 that affect rice tillering, we detected the expression of OsAAP4 in OsAAP3 and OsAAP5 transgenic plants. The result showed that the expression of OsAAP4 in basal part of OsAAP5 OE lines was higher, however, there was no consistent expression pattern in other transgenic plants (Supplementary file 13: Figure S13), suggesting that there is no direct relationship between OsAAP4 and OsAAP3 or OsAAP5 in rice tillering regulation. These results indicated that altered expression of OsAAP4 influenced bud outgrowth and rice tillering by coordinating nitrogen and phytohormone pathway.

\section{Discussion}

Here, we provide evidence to support the hypothesis that the amino acid transporter OsAAP4 contributes to rice tillering and grain yield by regulating neutral amino acid transport through two different splicing variants. First, we found that the expression level of OsAAP4 was higher in Indica than in Japonica and that upregulation of OsAAP4 in Japonica significantly increased tiller number, grain yield and NUtE. However, OsAAP3 and OsAAP5 of the rice amino acid transporter family, are highly expressed in Japonica rice (Lu et al. 2018; Wang et al. 2019a), and blocking OsAAP3 and OsAAP5 in Japonica rice enhances tiller number and grain yield ( $\mathrm{Lu}$ et al. 2018; Wang et al. 2019a). Previous studies have also demonstrated that the T-DNA insertion line ataap2 exhibits strongly increased branch and silique numbers per plant as well as seed yield (Zhang et al. 2010). In contrast, overexpression of PtAAP1 improves plant NUtE through alteration of amino acid transport from source-to-sink in pea (Perchlik and Tegeder, 2017). In rice, another organic nitrogen transporter of the NPF family, OsNPF7.3, transports di/tripeptides Gly-His and Gly-His-Gly (Ouyang et al. 2010) and positively 
influences rice tiller number and NUtE (Fang et al. 2017). A recent study reveals that the amino acid transporter OsAAP1 mediates growth and grain yield by regulating neutral amino acid uptake and reallocation in rice (Ji et al. 2020). Our study further indicated that as a result of artificial selection, different rice accessions are able to adapt to the environment by regulating expression of different AATs.

Second, the altered expression of OsAAP4 relatively influenced the contents of amino acids Val and Pro both in rice seedling and reproductive stage, and the elongation of tiller bud of OsAAP4 transgenic lines could also be regulated by exogenous amino acids Val and Pro, although the amino acid contents determined by HPLC can not distinguish the amino acids that were transported by OsAAP4 or altered indigenous synthesis. Furtermore, whether OsAAP4 can regulate the transport of these amino acids was verified using a new method of amino acid-FITC labeling and a protoplast uptake assay (Wang et al. 2019a; Ji et al. 2020), and we determined that both variants of OsAAP4 could regulate neutral amino acid transport in rice plant cells. Furthermore, the longer variant OsAAP4a regulated Val and Pro transport at low concentrations, whereas the shorter variant OsAAP4b regulated Val and Pro transport at high concentrations. In Arabidopsis, there is only one variant of AtAAP4, which transports Val and Pro (Fischer et al. 1995), though this protein grouped into different subclusters compared with rice OsAAP4. Recent insight into the origin and evolution of AAP proteins has revealed that AAP proteins are mainly found in land vascular plants and that algae lack AAPs (Tegeder and Ward, 2012). The divergence of AAP4 between rice and Arabidopsis indicates that different variants may play key roles in adapting to different soil nutritional conditions which encountered by rice in artificial cultivation. Similarly, there are two variants (OsNRT2.3a and OsNRT2.3b) of the rice high-affinity nitrate transporter OsNRT2.3, and OsNRT2.3b can sense $\mathrm{pH}$ changes in cells, thus facilitating the absorption of more nitrogen, iron and other nutrients (Fan et al. 2016). Overexpression of OsNRT2.3b might improve rice yield and NUtE (Fan et al. 2016). Recently, it was suggested that two splicing variants of OsNPF7.7 regulate tiller number and NUtE in rice, with OsNPF7.7a facilitating nitrate influx and concentration and OsNPF7.7b improving ammonium influx (Huang et al. 2018). Excitingly, our results indicate that two OE lines of OsAAP4 promote rice growth under different Val and Pro concentrations.

Additionally, the neutral amino acid Val is an important branched-chain amino acid, and disruptions in Val degradation affect seed development and germination in Arabidopsis (Gipson et al. 2017). Our study showed that Val promoted growth in rice plants, especially bud outgrowth for tillers (Fig. 5). Another neutral amino acid, Pro, is critical for rapid cell division in organ development (Venekamp and Koot 1984; Lehmann et al. 2010), because rapidly dividing and growing cells have a high demand for Pro (Székely et al. 2008). PtAAP11, the plant amino acid transporter with the highest affinity for Pro, is mainly expressed in shoot and root meristematic cells and facilitates bud development (Couturier et al. 2010). In our study, treatment with moderate Val and Pro concentrations promoted plant height, biomass, and bud outgrowth in two OE lines, consistent with the finding that exogenously applied Pro improved the in vitro shoot regeneration frequency of rice (Pawar et al. 2015).

In addition, Pro plays a role as a compatible solute under environmental stress conditions (Lehmann et al. 2010). The Glu pathway is the primary route for Pro synthesis in plants during conditions of osmotic stress and nitrogen limitation, whereas the ornithine pathway assumes prominence under high nitrogen input (Delauney et al. 1993). Therefore, AAP4a may divert Pro from the Glu synthesis pathway when nitrogen is limited, whereas AAP4b may acquire Pro from the ornithine synthesis pathway when nitrogen is abundant. Lys can inhibit mitotic activity in the root apical meristem, and higher exogenous Lys can reduce the length of the main root of Arabidopsis (Yang et al. 2014) and inhibit bud outgrowth in rice ( $\mathrm{Lu}$ et al. 2018; Wang et al. 2019a). OsAAP4 RNAi both reduced the concentration of neutral amino acids (Val and Pro) and increased that of basic amino acids (Lys and Arg), which may explain why $\mathrm{Ri}$ lines exhibited worse growth than wild-type ZH11. Downregulation of OsAAP4 affected bud outgrowth, plant height, and biomass by regulating neutral amino acids (Val and Pro) and basic amino acids (Lys and Arg) in rice.

Finally, tiller number is an important feature of the rice grain yield produced from bud initiation and elongation ( $\mathrm{Li}$ et al. 2003), and tiller bud outgrowth is regulated by both environmental signals and endogenous factors (Xing and Zhang 2010; Fang et al. 2020). Of all the nitrogen transporters characterized to date, only OsNPF8.20, OsNPF6.5, OsNPF7.3, OsNPF7.2, OsNPF7.7, and OsAAP1 can positively regulate rice tiller number and enhance grain yield (Fang et al. 2013; Hu et al. 2015; Fang et al. 2017; Wang et al. 2018; Huang et al. 2018; Ji et al. 2020). Our results indicated that overexpression of OsAAP4 also positively influences tiller number by regulating expression of OsNPF6.5 and OsNPF7.7 (Fig. 7c). Recently, the genes OsGS1;2 and OsGS2 were found to be highly expressed in the axillary buds under $5.0 \mathrm{mM}$ nitrogen (Wang et al. 2020), and further indicated that overexpression of OsGS1;2 and OsGS2 promote axillary bud growth and tiller number via ammonium assimilation, whereas reduced expression of GS1;2 affects the assimilation of ammonium into glutamine, resulting in decreased bud 
elongation and tiller number in rice (Ohashi et al. 2015; Wang et al. 2020). Similarly, our experiment also showed that expression of two genes OsGS1;2 and OsGS2 of the nitrogen pathway was increased in $\mathrm{OE}$ lines but decreased in Ri lines of OsAAP4. Taken together, these results demonstrate that altered expression of OsAAP4 influences bud outgrowth through the nitrogen and phytohormone pathway. It has been reported that the phytohormone cytokinin (CK) promotes tillering (Dun et al., 2012), while auxin can inhibit tillering (Leyser, 2003). Our study indicated that the expression of such CK crucial genes as OsCKX3 and OsCKX4 was lower in OE lines than in ZH11 (Fig. 7d), suggesting that CKs probably produced in larger amounts in OE lines than in ZH11. Moreover, the expression of OsYUCCA6, OsYUCCA7 was higher in OE lines than in ZH11, whereas the expression of OsPIN1c, OsPIN1d, OsPIN2, and OsPIN10b was lower in OE lines than in ZH11 (Fig. 7c), indicating that auxin may be decreased in the axillary buds of OsAAP4 OE lines, resulting in the induction of the axillary bud outgrowth.

\section{Conclusions}

In this study, we demonstrate that OsAAP4 promoter sequences are divergent between Indica and Japonica, and overexpression of two different splicing variants of OsAAP4 in Japonica ZH11 significantly promoted rice tillering and grain yield as result of enhancing the neutral amino acid concentrations. Importantly, OsAAP4 positively regulated tiller bud outgrowth probably by coordinating nitrogen transport and metabolism, and auxin, CK signaling pathway.

\section{Methods}

\section{Plasmid Construction}

To construct an OsAAP4a or OsAAP4b-overexpression plasmid, a 1407-bp fragment of OsAAP4a cDNA or a 1116-bp fragment of OsAAP4b cDNA containing the open reading frame (ORF) was inserted downstream of the $35 \mathrm{~S}$ promoter of the pCAM1306 vector digested using $K p n \mathrm{I}$ and $X b a I$, respectively, to produce p35S-OsAAP4a and $p 35 S-O s A A P 4 b$. To construct the OsAAP4-RNAi plasmid, two fragments of OsAAP4 cDNA (263 bp) were amplified by PCR and cloned downstream of the Ubi-1 promoter in the rice RNAi vector pTCK303 and digested by BamHI/ $K p n \mathrm{I}$ and SpeI/SacI, respectively. The OsAAP4 CRISPR plasmid was constructed using CRISPR/Cas9-based multiplex genome editing for monocot and dicot plants (Ma et al. 2015). To construct the OsAAP4 promoter-GUS plasmid, a sequence of approximately $2500 \mathrm{bp}$ upstream of the first ATG of OsAAP4 in Indica W144 was inserted upstream of the GUS gene in pCAM1391Z using HindIII and NcoI to produce $p W 144-G U S$, respectively. All primers used in this study are listed in Supplementary file 14: Table S1.

\section{Plant Materials}

Japonica Zhonghua 11 (ZH11) was transformed using Agrobacterium-mediated transformation, and transgenic calli were selected using $50 \mathrm{mg} \mathrm{L}^{-1}$ hygromycin. $\mathrm{T}_{2}$ homologous transgenic lines were used in all experiments. All transgenic plants and 497 sequencing accessions (Chen et al. 2014) were grown at the rice experimental base in Wuhan and Sanya of Huazhong Agricultural University, China. Tiller number and other agronomic traits were measured at the filling stage over three seasons from 2014 to 2018. In general, 30 rice plants were used for each experiment, and the planting density was $19.98 \mathrm{~cm} \times 19.98 \mathrm{~cm}$.

\section{RNA Extraction and PCR Analysis}

Total RNA was extracted using TRIzol reagent according to the manufacturer's instructions (TAKARA). Firststrand cDNA was synthesized from $3 \mu \mathrm{g}$ of total RNA treated with DNase I using M-MLV reverse transcriptase (TAKARA). The first-strand cDNA was used as the template for real-time quantitative PCR (RT-PCR) using normalization to rice Actin1 (LOC_Os03g50885). RTPCR was performed in a $20 \mu \mathrm{L}$ reaction volume containing $1 \mu \mathrm{L}$ of cDNA solution, $1 \times$ PCR buffer, $0.25 \mu \mathrm{M}$ dNTPs, $1.0 \mu \mathrm{M}$ gene-specific primers and $0.5 \mathrm{U}$ of Taq polymerase (Takara) with the following conditions: $94{ }^{\circ} \mathrm{C}$ for $2 \mathrm{~min}(1 \mathrm{cycle}) ; 94{ }^{\circ} \mathrm{C}$ for $30 \mathrm{~s}, 55^{\circ} \mathrm{C}$ for $30 \mathrm{~s}$, and $72^{\circ} \mathrm{C}$ for $30 \mathrm{~s}$ ( 40 cycles); and $72^{\circ} \mathrm{C}$ for $1 \mathrm{~min}$ ( 1 cycle). Amplification of the cDNA or promoter sequence of OsAAP4 was performed in a $20 \mu \mathrm{L}$ reaction volume containing $1 \mu \mathrm{L}$ of cDNA or DNA solution, $1 \times$ PCR buffer, $0.5 \mu \mathrm{M}$ dNTPs, $1.0 \mu \mathrm{M}$ gene-specific primers and $0.5 \mathrm{U}$ of Taq polymerase (Takara) with the following conditions: $94{ }^{\circ} \mathrm{C}$ for $3 \mathrm{~min}(1 \mathrm{cycle}) ; 94{ }^{\circ} \mathrm{C}$ for $30 \mathrm{~s}, 48-65^{\circ} \mathrm{C}$ for $30 \mathrm{~s}$, and $72{ }^{\circ} \mathrm{C}$ for $2 \mathrm{~min}$ (30-40 cycles); and $72{ }^{\circ} \mathrm{C}$ for $10 \mathrm{~min}$ ( 1 cycle).

\section{Amino Acid and Total Nitrogen Analyses}

Total and single free amino acid concentrations were measured by HPLC with an amino acid analyzer L-8800 HITACHI. The samples were prepared as follows. Rice tissue $(1 \mathrm{~g})$ was placed in $80 \%$ ethanol $(10 \mathrm{ml})$ at $80^{\circ} \mathrm{C}$ in a water bath for $20 \mathrm{~min}$; this step was repeated twice. The collected extracts were placed at $80^{\circ} \mathrm{C}$ in a drying oven to remove the ethanol, and the sediment was dissolved in $1 \mathrm{ml} 0.5 \mathrm{M} \mathrm{NaOH}$. The solution was centrifuged at $14,000 \mathrm{rpm}$ for $15 \mathrm{~min}$. The supernatant was collected and filtered through a filter membrane $(2 \mu \mathrm{m})$; $0.8 \mathrm{ml}$ of each filtrate was analyzed using an amino acid analyzer. The total nitrogen content and total protein content were determined using the semi-micro Kjeldahl method with a nitrogen analyzer (Smart Chem 200). Nitrogen utilization efficiency was determined using the 
formula: NUtE $(\%)=$ [grain yield $(\mathrm{g}) /$ (grain nitrogen content $(\mathrm{g})+$ straw nitrogen content $(\mathrm{g})] \times 100$.

\section{GUS Staining}

GUS staining of $p W 144-G U S$ of OsAAP4 promoter-GUS transgenic plants was performed as described previously (Fang et al. 2017). All samples for GUS staining were vacuum infiltrated for $15 \mathrm{~min}$ and gently fixed in FAA (formalin-acetic acid-70\% ethanol [1:1:18]) at $4 .{ }^{\circ} \mathrm{C}$ for 20-30 min. The samples were then incubated in staining buffer at $37^{\circ} \mathrm{C}$ overnight. After removing chlorophyll by incubation in a solution of $80 \%$ ethanol, the stained samples were observed using a stereomicroscope OLYMPUS SZX16. Finally, the samples were embedded in Spurr resin and sectioned. The sections were observed using a Zeiss Axio Imager M2.

\section{Hydroponic Culture and Plant Growth Observation}

Transgenic OsAAP4 plants were cultured in basic nutri-

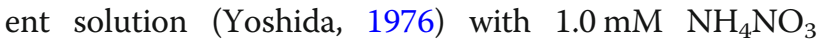
under natural rice growth conditions, and individual amino acids were adjusted in each experiment. To investigate the effect of neutral amino acids Val and Pro on the phenotype of OsAAP4-transgenic plants, seedlings were grown in basic rice culture solution with $1.0 \mathrm{mM}$ $\mathrm{NH}_{4} \mathrm{NO}_{3}$ as the $\mathrm{N}$ source for 1 week and transferred to basic rice culture solution supplemented with $1.0 \mathrm{mM}$ $\mathrm{NH}_{4} \mathrm{NO}_{3}$ and each amino acid as the $\mathrm{N}$ source. To assess axillary bud outgrowth, the first and second bud lengths of axillary buds were measured using a stereomicroscope and Image J software from 28 days after sowing. For hydroponic culture, different transgenic seedlings were grown in boxes $(525 \mathrm{~mm} \times 360 \mathrm{~mm} \times 230$ $\mathrm{mm}$ ) in rice culture solution under greenhouse conditions of $32{ }^{\circ} \mathrm{C}$ with a sodium lamp at $400 \mathrm{~W}$ for $14 \mathrm{~h}$ (daytime) and $25^{\circ} \mathrm{C}$ for $10 \mathrm{~h}$ (nighttime). The nutrient solution was renewed every 3 days.

\section{Protoplast Amino Acid Uptake Assay}

Amino acids labeled with FITC (Val-FITC, Pro-FITC, Thr-FITC and Leu-FITC, Arg-FITC, Lys-FITC) were synthesized by Yuan Peptide Biotechnology Company, Nanjing, China, as fluorescently tagged $\mathrm{GA}_{3}$-FITC in elongating endodermal cells of roots in Arabidopsis (Tal et al. 2016), and a protoplast biomolecule uptake assay was performed as previously described (Rottmann et al. 2018; Ji et al. 2020). Rice protoplasts prepared from etiolated seedlings of ZH11 and transgenic lines were incubated in $1 \mathrm{ml} \mathrm{W5}$ buffer ( $\mathrm{pH}$ 5.6) with each FITC-labeled amino acid at room temperature in the dark. Four hours later, the protoplasts were washed eight times to remove free amino acids, and fluorescence was observed using a confocal laser scanning microscope (Leica SP8). Rice protoplast cells with fluorescent amino acids were found at $10 \times 100$ times under the excitation light with a wavelength of $488 \mathrm{~nm}$. The fluorescence intensity was modulated by $20 \%$, and the photo resolution was $2048 \times 2048$.

\section{Subcellular Localization}

For subcellular localization of two variants of OsAAP4, OsAAP4a or OsAAP4b, the ORF was amplified and fused with green fluorescent protein (GFP) in the pCAM1302 vector to generate the p35S:OsAAP4a-GFP and p35S: OsAAP4b-GFP plasmid. The plasmid was transiently expressed in rice protoplasts prepared from etiolated seedlings of ZH11, and fluorescence was observed using a confocal laser scanning microscope (Leica SP8). The Agrobacterium strain GV3101 transformed with p35S: OsAAP4a-GFP and p35S:OsAAP4b-GFP was infiltrated into 1-month-old $N$. benthamiana plants to study the transient expression of OsAAP4. The DAPI, GFP, and FM4-64 fluorescence signals were detected at $2 \mathrm{~d}$ postinjection using a confocal laser scanning microscope (Leica SP8).

\section{RNA-Seq Analysis}

The axillary buds from transgenic OsAAP4 plants and the wild-type ZH11 plants were collected for RNA sequencing (RNA-seq), analysis and two biological replicates were performed for each sample by Novogene. The clean data were aligned to the rice genome reference sequence (Oryza_sativa. IRGSP-1.0) by HiSAT2 (v2.1.0) (Kim et al. 2015). Transcripts were then assembled by stringtie (v2.0.1) (Pertea et al. 2016) and then processed by feature Counts to summarize the counting reads (subread-2.0.0) (Liao et al. 2014). The intersection of differential genes analyzed by DESeq2 [false discovery rate $($ FDR $)<0.05$ and fold change $\geq 2$ ] were identified as differentially expressed genes (DEGs) (Love et al. 2014).

\section{Statistical Analysis}

Differences were analyzed using Student's $t$ and Duncan test, with the following significance levels: ${ }^{* * *} P<0.001$; ${ }^{* *} P<0.01 ; * P<0.05$ or letters at $P<0.05$.

\section{Supplementary Information}

The online version contains supplementary material available at https://doi. org/10.1186/s12284-020-00446-9.

Additional file 1: Figure S1. Expression levels of OSAAP4 in young seedling root (a), basal part (b), old leaf $(\mathbf{c})$, young leaf $(\mathbf{d})$ between Hap2 and Hap5 of five individual varieties. The primers used for quantifying OsAAP4 expression was F: GACATCGTCCACAACCTCAAGGCT, and R: GCCA CAGCTCTAGCTAGGCAGC. Values are means \pm s.d. $(n=3)$.

Additional file 2: Figure S2. Sequencing of two different types of promoter sequences of OsAAP4. NIP indicates Nipponbare, C172 indicates the Hap5 type in Japonica. W144 indicates the Hap2 type in Indica.

Additional file 3: Figure S3. Expression levels of OSAAP4a (a) and OsAAP4b (b) in young seedling basal part between Hap2 and Hap5 of five individual varieties. The primers used for quantifying OsAAP4a 
expression was F: TGGCACTCACCCTTGCACAC, and R: CCGTCCACACCGTC CCTTGT, for quantifying OSAAP4b expression was ACTTGAGCTCTCTGCATT GGGT, and R: AGCGGTAGCAATTGGCGAGGA. Values are means \pm s.d. ( $n=$ 3).

Additional file 4: Figure S4. Subcellular localization of OsAAP4. (a-e) Localization of the 355 promoter-driven GFP as the control in rice protoplasts. (f-j) Localization of the OsAAP4a-GFP in rice protoplasts. (k-o) Localization of the OsAAP4b-GFP in rice protoplasts. (p-s) Localization of OsAAP4a-GFP in tobacco pavement cells. (t-w) Localization of OsAAP4bGFP in tobacco pavement cells. Green, GFP signal. Blue, DAPI (a nuclear marker) signal. Red, FM4-64 (a lipophilic membrane marker) signal. DIC, bright field. Scale bars represent $5 \mu \mathrm{m}$ in (a-o) and $25 \mu \mathrm{m}(\mathbf{p}-\mathbf{w})$.

Additional file 5: Figure S5. Knockout of OSAAP4 significantly decreased NUtE in rice Japonica ZH11 using CRISPR technology. a Sequencing results of the base addition of OSAAP4-CRISPR in Japonica ZH11 with CRISPR technology. Whole-plant phenotype (b) and grain yield per plant (c) of ZH11 and OSAAP4-CRISPR lines in the ZH11 background. Quantification of tiller number per plant (d), filled grain yield per plant (e), grain yield per plant $(\mathbf{f})$, and NUtE $(\mathbf{g})$ of ZH11 and OSAAP4-CRISPR lines. The letters above the error bars are ranked by the $T$ test, "****" indicates a significant difference at $p<0.001$. Scale bars, $5.0 \mathrm{~cm}(\mathbf{b}), 3.0 \mathrm{~cm}(\mathbf{c})$ Values are means \pm s.d. $(n>20)$.

Additional file 6: Figure S6. Phenotypic analysis of OSAAP4 transgenic plants in the Japonica ZH11 background grown in Sanya paddy fields. (a) Whole-plant phenotype. (b) Tiller number per plant. OEa-1 and OEa-2 indicate long variants of OsAAP4a-overexpressing lines, OEb-1 and OEb-2 indicate short variants OsAAP4b-overexpressing lines, Ri-1 and Ri-2 indicate OSAAP4-RNAi lines, and osaap4 indicates OSAAP4-CRISPR line. The letters above the error bars are ranked by the $T$ test, "** indicates a significant difference at $p<0.05$, and "***" indicates a significant difference at $p<0.001$. Scale bar, $10.0 \mathrm{~cm}(\mathbf{a})$. Values are means \pm s.d. $(\mathbf{n}>20)$.

Additional file 7: Figure S7. Total free amino acid concentration of basal parts at seedlings stage and straw at filling stage. OEa, OEb, and Ri indicated that mixed equal-amount which extracted from each three OEa, OEb, and Ri lines, respectively. The letters above the error bars are ranked by the $T$ test, "**" indicates a significant difference at $p<0.05$, and "***" indicates a significant difference at $p<0.01$. Values are means \pm s.d. $(n=3)$.

Additional file 8: Figure S8. Effect of different concentrations of Val and Pro on the growth of ZH11, OEa, OEb, and Ri lines grown in hydroponic culture. Phenotypes of seedlings among ZH11, OEa, OEb, and Ri lines grown with $1.0 \mathrm{mM} \mathrm{NH} \mathrm{NO}_{3}$ and Val $0.5 \mathrm{mM}(\mathbf{a})$, Val $2.0 \mathrm{mM}(\mathbf{b})$, Pro $0.5 \mathrm{mM}(\mathbf{c})$, and Pro $2.0 \mathrm{mM}(\mathbf{d})$. Quantification of plant height (e) and biomass (f) under Val $0.5 \mathrm{mM}$ and Val $2.0 \mathrm{mM}$ treatment.

Quantification of plant height $(\mathbf{g})$ and biomass $(\mathbf{h})$ under Pro $0.5 \mathrm{mM}$ and Pro $2.0 \mathrm{mM}$ treatment. The letters above the error bars are ranked by the $\mathrm{T}$ test, "**" indicates a significant difference at $p<0.05$, "**" indicates a significant difference at $p<0.01$, and "****" indicates a significant difference at $p<0.001$. Scale bar, $10.0 \mathrm{~cm}(\mathrm{a}-\mathrm{d})$. Values are means \pm s.d. $(n>15)$.

Additional file 9: Figure S9. Protoplast amino acid-uptake assay among Z $\mathrm{H} 11, \mathrm{OEa}, \mathrm{OEb}$, and Ri lines. Fluorescence was detected after culturing protoplasts with FITC-labeled amino acids for $4 \mathrm{~h}$. Green fluorescence images of $\mathrm{ZH} 11$ and OEa, OEb and Ri lines under treatment with $0.5 \mathrm{mM}$ Arg-FITC (a), $0.5 \mathrm{mM}$ Lys-FITC (b), $0.5 \mathrm{mM}$ Thr-FITC (c), and 0.5 mM Leu-FITC (d). e Detection of cell fluorescence signal intensity in (a-d) Fluorescence intensities were normalized to the area of the respective cell by ImageJ software, and a total of 100 cells were statistically analyzed. Scale bars, $5.0 \mu \mathrm{m}(\mathbf{a}-\mathbf{d})$. The letters above the error bars are ranked by the T test, ${ }^{\prime * \prime \prime}$ indicates a significant difference at $p<0.05,{ }^{\prime * * * \prime}$ indicates a significant difference at $p<0.01$, and " $* * * *$ indicates a significant difference at $p<0.001$. Values are means \pm s.d. $(\mathbf{n}=3)$.

Additional file 10: Figure S10. KEGG enrichment analysis of the DEGs in the axillary buds of genes that are respectively regulated by OEa lines (a), OEb lines (b) compared with the wild-type ZH11. Gene ratio indicates that the ratio of the DEG number and the number of genes has been annotated in this pathway.

Additional file 11: Figure S11. KEGG enrichment analysis of the DEGs in the axillary buds of genes that are jointly regulated by OEa and OEb lines compared with the wild-type $\mathrm{ZH} 11$. Gene ratio indicates that the ratio of the DEG number and the number of genes has been annotated in this pathway.

Additional file 12: Figure S12. Heatmap visualization of expression profiles of DEGs in OsAAPs regulated by OsAAP4 OEa and OEb lines compared with the wild-type ZH11. Red boxes show up-regulation, and green boxes show down-regulation. " $*$ " indicates a significant difference at $P$-value $<0.05$ and fold change $>2$.

Additional file 13: Figure S13. The expression of OSAAP4 in basal part of OSAAP3 and OSAAP5 transgenic plants. The primers used for quantifying OSAAP4 expression was F: GACATCGTCCACAACCTCAAGGCT, and R: GCCACAGCTCTAGCTAGGCAGC. The letters above the error bars are ranked by the $T$ test, ${ }^{\prime * * * *}$ indicates a significant difference at $p<$ 0.001 . Values are means $\pm S D(n=3)$.

Additional file $\mathbf{1 4}$ Table S1. List of the primers in this study.

\section{Abbreviations}

AAP: Amino acid permease; AAT: Amino acid transporter; Arg: Arginine; Asp: Aspartic acid; CK: Cytokinin; CRISPR: Clustered regularly interspaced short palindromic repeats; Cys: Cysteine; DEG: Differentially expressed gene; FDR: False discovery rate; FITC: Fluorescein isothiocyanate; GFP: Green fluorescent protein; Glu: Glutamic acid; Gly: Glycine; GUS: $\beta$-glucuronidase; Haplotype: Hap; HPLC: High performance liquid chromatography; Ile: Isoleucine; KEGG: Kyoto encyclopedia of genes and genomes; Leu: Leucine; Lys: Lysine; NutE: Nitrogen utilization efficiency; OE: Overexpression/Overexpresing; ORF: Open reading frame; Phe: Phenylalanine: Pro: Proline; Ri: RNA interference; RNA-seq: RNA sequencing; RT-PCR: Realtime quantitative PCR; Ser: Serine; SNP: Single-nucleotide polymorphisms; Thr: Threonine; Tyr: Tyrosine; Val: Valine; ZH11: Zhonghua 11

\section{Acknowledgments}

The authors would like to thank Jie Wu and Qingyun Guo (Huazhong Agricultural University) for kindly providing technical support.

\section{Authors' Contributions}

ZF designed the research, analyzed the data, and drafted the manuscript. ZF and BW performed the experiments. YJ performed the analysis of transcriptomes. All authors read and approved the final manuscript.

\section{Funding}

This research was supported by the grants from the National Key Research and Development Program (2016YFD0100700), the National Natural Science Foundation (31301250), Gui Da Zhuan Ji He Zi (2019) 07 (702646193301) and the Guangdong Provincial Key Laboratory of Applied Botany, South China Botanical Garden, Chinese Academy of Sciences (AB2018022).

\section{Availability of Data and Materials}

All data supporting the conclusions of this article are provided within the article (and its additional files).

\section{Ethics Approval and Consent to Participate}

Not applicable.

\section{Consent for Publication}

Not applicable.

\section{Competing Interests}

The authors declare that they have no competing interests.

Received: 6 August 2020 Accepted: 6 December 2020

Published online: 06 January 2021

\section{References}

Boorer KJ, Fischer WN (1997) Specificity and stoichiometry of the Arabidopsis $\mathrm{H}^{+} /$ amino acid transporter AAP5. J Biol Chem 272:13040-13046

Chen W, Gao Y, Xie W, Gong L, Lu K, Wang W, Li Y, Liu X, Zhang H, Dong H, Zhang W, Zhang L, Yu S, Wang G, Lian X, Luo J (2014) Genome-wide association analyses provide genetic and biochemical insights into natural variation in rice metabolism. Nat Genet 46:714 
Couturier J, de Fay E, Fitz M, Wipf D, Blaudez D, Chalot M (2010) PtAAP11, a high affinity amino acid transporter specifically expressed in differentiating xylem cells of poplar. J Exp Bot 61:1671-1682

Delauney AJ, Hu CA, Kishor PB, Verma DP (1993) Cloning of ornithine deltaaminotransferase cDNA from Vigna aconitifolia by trans-complementation in Escherichia coli and regulation of proline biosynthesis. J Biol Chem 268 : 18673-18678

Dun EA, de Saint GA, Rameau C, Beveridge CA (2012) Antagonistic action of strigolactone and cytokinin in bud outgrowth control. Plant Physiol 158:487-498

Fan X, Tang Z, Tan Y, Zhang Y, Luo B, Yang M, Lian X, Shen Q, Miller AJ, Xu G (2016) Overexpression of a $\mathrm{pH}$-sensitive nitrate transporter in rice increases crop yields. Proc Natl Acad Sci U S A 113:7118-7123

Fang Z, Bai G, Huang W, Wang Z, Wang X, Zhang M (2017) The rice peptide transporter OsNPF7.3 is induced by organic nitrogen, and contributes to nitrogen allocation and grain yield. Front plant Sci 8:1338

Fang Z, Xia K, Yang X, Grotemeyer MS, Meier S, Rentsch D, Xu X, Zhang M (2013) Altered expression of the PTR/NRT1 homologue OsPTR9 affects nitrogen utilization efficiency, growth and grain yield in rice. Plant Biotech J 11:446-458

Fang ZM, Ji YY, Hu J, Guo RK, Sun SY, Wang XL (2020) Strigolactones and brassinosteroids antagonistically regulate the stability of D53-OsBZR1 complex to determine FC1 expression in rice tillering. Mol Plant 13:586-597

Fischer WN, Kwart M, Hummel S, Frommer WB (1995) Substrate specificity and expression profile of amino acid transporters (AAPs) in Arabidopsis. J Biol Chem 270:16315-16320

Fischer WN, Loo DD, Koch W, Ludewig U, Boorer KJ, Tegeder M, Rentsch D, Wright EM, Frommer WB (2002) Low and high affinity amino acid H+cotransporters for cellular import of neutral and charged amino acids. Plant J 29:717-731

Garneau MG, Tan Q, Tegeder M (2018) Function of pea amino acid permease AAP6 in nodule nitrogen metabolism and export, and plant nutrition. J Exp Bot 69:5205-5219

Gipson AB, Morton KJ, Rhee RJ, Simo S, Clayton JA, Perrett ME, Binkley CG, Jensen EL, Oakes DL, Rouhier MF, Rouhier KA (2017) Disruptions in valine degradation affect seed development and germination in Arabidopsis. Plant J 90:1029-1039

Guo N, Gu M, Hu J, Qu H, Xu G (2020b) Rice OsLHT1 functions in leaf-to-panicle nitrogen allocation for grain yield and quality. Front plant Sci 11:1150.

Guo N, Hu J, Yan M, Qu H, Luo L, Tegeder M, Xu G (2020a) Oryza sativa lysineHistidine-type transporter 1 functions in root uptake and root-to-shoot allocation of amino acids in rice. Plant J 103:395-411

Hirner B, Fischer WN, Rentsch D, Kwart M, Frommer WB (1998) developmental control of $\mathrm{H}+$ /amino acid permease gene expression during seed development of Arabidopsis. Plant J 14:535-44.

Hu B, Wang W, Ou S, Tang J, Li H, Che R, Zhang Z, Chai X, Wang H, Wang Y, Liang C, Liu L, Piao Z, Deng Q, Deng K, Xu C, Liang Y, Zhang L, Li L, Chu C (2015) Variation in NRT1.1B contributes to nitrate-use divergence between rice subspecies. Nat. Genet 47:834-838

Huang W, Bai G, Wang J, Zhu W, Zeng Q, Lu K, Sun S, Fang Z (2018) Two splicing variants of OsNPF7.7 regulate shoot branching and nitrogen utilization efficiency in rice. Front. Plant Sci 9:300

Hunt E, Gattolin S, Newbury HJ, Bale JS, Tseng HM, Barrett DA, Pritchard J (2010) A mutation in amino acid permease AAP6 reduces the amino acid content of the Arabidopsis sieve elements but leaves aphid herbivores unaffected. J Exp Bot 61:55-64

Ji YY, Huang WT, Wu BW, Fang ZM, Wang XL (2020) The amino acid transporter AAP1 mediates growth and grain yield by regulating neutral amino acid uptake and reallocation in Oryza sativa. J Exp Bot 71:4763-777

Jin C, Sun YY, Shi YH, Zhang YY, Chen K, Li Y, Liu GG, Yao F, Cheng D, Li J, Zhou JJ, Qu LH, Liu XQ, Luo J (2019) Branched-chain amino acids regulate plant growth by affecting the homeostasis of mineral elements in rice. Sci China Life Sci 62:1107-1110

Kim D, Langmead B, Salzberg SL (2015) HISAT: a fast spliced aligner with low memory requirements. Nat Methods 12:357-360

Koch W, Kwart M, Laubner M, Heineke D, Stransky H, Frommer WB, Tegeder M (2003) Reduced amino acid content in transgenic potato tubers due to antisense inhibition of the leaf $\mathrm{H}+$ /amino acid symporter StAAP1. Plant J 33: 211-220

Lee YH, Foster J, Chen J, Voll LM, Weber AP, Tegeder M (2007) AAP1 transports uncharged amino acids into roots of Arabidopsis. Plant J 50:305-319
Lehmann S, Funck D, Szabados L, Rentsch D (2010) Proline metabolism and transport in plant development. Amino Acids 39:949-962

Leyser O (2003) Regulation of shoot branching by auxin. Trends Plant Sci 8:541-545 Li X, Qian Q, Fu Z, Wang Y, Xiong G, Zeng D, Wang X, Liu X, Teng S, Hiroshi F, Yuan M, Luo D, Han B, Li J (2003) Control of tillering in rice. Nature 422:618-621

Liao Y, Smyth GK, Shi W (2014) FeatureCounts: an efficient general purpose program for assigning sequence reads to genomic features. Bioinformatics 30:923-930

Liu D, Gong W, Bai Y, Luo JC, Zhu YX (2005) OsHT, a rice gene encoding for a plasma-membrane localized histidine transporter. J Integr Plant Biol 47:92-99

Love Ml, Huber W, Anders S (2014) Moderated estimation of fold change and dispersion for RNA-seq data with DESeq2. Genome Biol 15:550

Lu K, Wu B, Wang J, Zhu W, Nie H, Qian J, Huang W, Fang Z (2018) Blocking amino acid transporter OSAAP3 improves grain yield by promoting outgrowth buds and increasing tiller number in rice. Plant Biotech J 16: $1710-1722$

Ma X, Zhang Q, Zhu Q, Liu W, Chen Y, Qiu R, Wang B, Yang Z, Li H, Lin Y, Xie Y, Shen R, Chen S, Wang Z, Chen Y, Guo J, Chen L, Zhao X, Dong Z, Liu YG (2015) A robust CRISPR/Cas9 system for convenient, high-efficiency multiplex genome editing in monocot and dicot plants. Mol Plant 8:1274-1284

Miranda M, Borisjuk L, Tewes A, Heim U, Sauer N, Wobus U, Weber H (2001) Amino acid permeases in developing seeds of Vicia faba L.: expression precedes storage protein synthesis and is regulated by amino acid supply. Plant J 28:61-71

Ohashi M, Ishiyama K, Kusano M, Fukushima A, Kojima S, Hanada A, Kanno K, Hayakawa T, Seto Y, Kyozuka J, Yamaguchi S, Yamaya T (2015) Lack of cytosolic glutamine synthetase 1;2 in vascular tissues of axillary buds causes severe reduction in their outgrowth and disorder of metabolic balance in rice seedlings. Plant J 81:347-356

Okumoto S, Koch W, Tegeder M, Fischer WN, Biehl A, Leister D, Stierhof YD, Frommer WB (2004) Root phloem-specific expression of the plasma membrane amino acid proton co-transporter AAP3. J Exp Bot 55:2155-2168

Okumoto S, Schmidt R, Tegeder M, Fischer WN, Rentsch D, Frommer WB, Koch W (2002) High affinity amino acid transporters specifically expressed in xylem parenchyma and developing seeds of Arabidopsis. J Biol Chem 277:4533845346

Ouyang J, Cai Z, Xia K, Wang Y, Duan J, Zhang M (2010) Identification and analysis of eight peptide transporter homologs in rice. Plant Sci 179:374-382

Pawar B, Kale P, Bahurupe J, Jadhav A, Kale A, Pawar S (2015) Proline and glutamine improve in vitro callus induction and subsequent shooting in rice. Rice Sci 22:283-289

Peng B, Kong H, Li Y, Wang L, Zhong M, Sun L, Gao G, Zhang Q, Luo L, Wang G, Xie W, Chen J, Yao W, Peng Y, Lei L, Lian X, Xiao J, Xu C, Li X, He Y (2014) OsAAP6 functions as an important regulator of grain protein content and nutritional quality in rice. Nat Commun 5:4847

Perchlik M, Tegeder M (2017) Improving plant nitrogen use efficiency through alteration of amino acid transport processes. Plant Physiol 175:235-247

Pertea M, Kim D, Pertea GM, Leek JT, Salzberg SL (2016) Transcript level expression analysis of RNA-seq experiments with HISAT, StringTie and Ballgown. Nat Protoc 11:1650-1667

Pratelli R, Pilot G (2014) Regulation of amino acid metabolic enzymes and transporters in plants. J Exp Bot 65:5535-5556

Rottmann TM, Fritz C, Lauter A, Schneider S, Fischer C, Danzberger N, Dietrich P, Sauer N, Stadler R (2018) Protoplast-esculin assay as a new method to assay plant sucrose transporters: characterization of AtSUC6 and AtSUC7 sucrose uptake activity in Arabidopsis Col-0 ecotype. Front Plant Sci 9:430

Sanders A, Collier R, Trethewy A, Gould G, Sieker R, Tegeder M (2009) AAP1 regulates import of amino acids into developing Arabidopsis embryos. Plant 59:540-552

Santiago JP, Tegeder M (2016) Connecting source with sink: the role of Arabidopsis AAP8 in phloem loading of amino acids. Plant Physiol 171:508521

Schmidt R, Stransky H, Koch W (2007) The amino acid permease AAP8 is important for early seed development in Arabidopsis thaliana. Planta 226 805-813

Svennerstam H, Ganeteg U, Nasholm T (2008) Root uptake of cationic amino acids by Arabidopsis depends on functional expression of amino acid permease 5. New Phytol 180:620-630

Székely G, Abrahám E, Cséplo A, Rigó G, Zsigmond L, Csiszár J, Ayaydin F, Strizhov N, Jásik J, Schmelzer E, Koncz C, Szabados L (2008) Duplicated P5CS 
genes of Arabidopsis play distinct roles in stress regulation and developmental control of proline biosynthesis. Plant J 53:11-28

Tal I, Zhang Y, Jørgensen ME, Pisanty O, Barbosa IC, Zourelidou M, Regnault T, Crocoll C, Olsen CE, Weinstain R, Schwechheimer C, Halkier BA, Nour-Eldin $\mathrm{HH}$, Estelle M, Shani E (2016) The Arabidopsis NPF3 protein is a GA transporter. Nat Commun 7:11486

Tan QM, Grennan AK, Pelissier HC, Rentsch D, Tegeder M (2008) Characterization and expression of French bean amino acid transporter PVAAP1. Plant Sci 174 348-356

Taylor MR, Reinders A, Ward JM (2015) Transport function of rice amino acid permeases (AAPs). Plant Cell Physiol 56:1355-1363

Tegeder M (2012) Transporters for amino acids in plant cells: some functions and many unknowns. Curr Opin Plant Biol 15:315-321

Tegeder M (2014) Transporters involved in source to sink partitioning of amino acids and ureides: opportunities for crop improvement. J Exp Bot 65:18651878

Tegeder M, Masclaux-Daubresse C (2018) Source and sink mechanisms of nitrogen transport and use. New Phytol 217:35-53

Tegeder M, Rentsch D (2010) Uptake and partitioning of amino acids and peptides. Mol Plant 3:997-1011

Tegeder M, Ward JM (2012) Molecular evolution of plant AAP and LHT amino acid transporters. Front Plant Sci 3:21

Venekamp JH, Koot JTM (1984) The distribution of free amino acids, especially of proline, in the organs of field bean plants. Vicia faba L., during development in the field. J Plant Physiol 116:343-349

Wang J, Lu K, Nie H, Zeng Q, Wu B, Qian J, Fang Z (2018) Rice nitrate transporter OsNPF7.2 positively regulates tiller number and grain yield. Rice 11:12

Wang J, Wu BW, Lu K, Wei Q, Qian JJ, Chen YP, Fang ZM (2019a) The amino acid Permease 5 (OsAAP5) regulates tiller number and grain yield in rice. Plant Physiol 180:1031-1045

Wang RN, Qian JJ, Fang ZM, Tang JH (2020) Transcriptomic and physiological analyses of rice seedlings under different nitrogen supplies provide insight into the regulation involved in axillary bud outgrowth. BMC Plant Biol 20:197

Wang X, Yang G, Shi M, Hao D, Wei Q, Wang Z, Shan F, Su Y, Xia J (2019b) Disruption of an amino acid transporter LHT1 leads to growth inhibition and low yields in rice. BMC Plant Biol 19:268

Xing Y, Zhang Q (2010) Genetic and molecular bases of rice yield. Annu Rev Plant Biol 61:421-442

Xu G, Fan X, Miller AJ (2012) Plant nitrogen assimilation and use efficiency. Annu Rev Plant Biol 63:153-182

Yang H, Postel S, Kemmerling B, Ludewig U (2014) Altered growth and improved resistance of Arabidopsis against Pseudomonas syringae by overexpression of the basic amino acid transporter AtCAT1. Plant Cell Env 37:1404-1414

Yoshida S, Forno DA, Cook JH, Gomez KA (1976) Routine procedures for growing rice plants in culture solution. In: Laboratory manual for physiological studies of Rice. International Rice Research Institute, Los Banos, pp 61-66

Zhang L, Tan Q, Lee R, Trethewy A, Lee YH, Tegeder M (2010) Altered xylemphloem transfer of amino acids affects metabolism and leads to increased seed yield and oil content in Arabidopsis. Plant Cell 22:3603-3620

Zhang LZ, Garneau MG, Majumdar R, Grant J, Tegeder M (2015) Improvement of pea biomass and seed productivity by simultaneous increase of phloem and embryo loading with amino acids. Plant J 81:134-146

\section{Publisher's Note}

Springer Nature remains neutral with regard to jurisdictional claims in published maps and institutional affiliations.

\section{Submit your manuscript to a SpringerOpen ${ }^{\odot}$ journal and benefit from:}

- Convenient online submission

- Rigorous peer review

- Open access: articles freely available online

- High visibility within the field

- Retaining the copyright to your article

Submit your next manuscript at $\boldsymbol{\nabla}$ springeropen.com 